\title{
Intrazeolite Synthesis of Polythiophene Chains
}

\author{
Patricia Enzel and Thomas Bein* \\ Department of Chemistry, University of New Mexico, Albuquerque, NM 87131, U.S.A.
}

\begin{abstract}
Adsorption of thiophene and 3-methylthiophene into the channel system of transition metal-containing zeolites $Y$ and mordenite results in oxidative polymerization to give encapsulated chains of polythiophene and poly(3-methylthiophene).
\end{abstract}

The design of well defined conducting polymers is of current interest in the context of fundamental studies of transport mechanism and of potential applications in microelectronics, coatings, and composite materials. ${ }^{1}$ Provided that structural features and control of electronic transport properties can be achieved at the molecular level, low-dimensional conductors offer the potential to reduce electronic circuitry to molecular dimensions. ${ }^{2}$ We study the inclusion of conductive polymers in the crystalline channel systems of zeolites as a promising avenue to design isolated, well defined chains of molecular conductors. In this Communication, we report the first successful polymerization of polythiophene (PTh) and poly(3methylthiophene $)^{3}$ (P3MTh) as polymeric chain conductors in zeolites. Zeolites are open-framework aluminosilicates with pore sizes of $0.3-1.2 \mathrm{~nm}$, and exchangeable cations compensating for the negative charge of the framework. ${ }^{4}$ Zeolite $\mathrm{Y}$ is characterized by interconnected 'sodalite' cages forming a three-dimensional open framework structure. Mordenite (M) features a pseudo-one-dimensional twelve-ring channel system. Both structures have an open pore size of about 0.7 $\mathrm{nm}$. Zeolite $\mathrm{A}$ has a framework composed of sodalite cages interconnected via double four-rings, with pore-openings of about $0.4 \mathrm{~nm}$. Although there have been reports on the formation of conducting polymers in the presence of zeolites, the polymerization products appeared to be restricted to the zeolite crystal surfaces. ${ }^{5}$ At a larger scale, polythiophene has been intercalated into the interlamellar space of FeOCl. 6

Intrazeolite $\mathrm{Cu}^{\mathrm{II}}$ and $\mathrm{Fe}{ }^{\mathrm{III}}$ ions, introduced via ion-exchange followed by dehydration in oxygen and vacuum $\left(10^{-5}\right.$ Torr, $620 \mathrm{~K}$ ), serve as oxidants for the oxidative polymerization 7,8 reaction. In the case of the $\mathrm{Fe}^{\mathrm{II}}$-zeolites, this treatment causes oxidation to $\mathrm{Fe}^{\mathrm{III}}$. Representative zeolite hosts have unit cell metal contents $\mathrm{Na}_{56} \mathrm{Y}, \mathrm{Cu}_{15} \mathrm{Na}_{26} \mathrm{Y}, \mathrm{Na}_{8} \mathrm{M}, \mathrm{Cu}_{2.4} \mathrm{Na}_{3.2} \mathrm{M}$, and $\mathrm{Cu}_{8} \mathrm{Na}_{80} \mathrm{~A}$. The monomers were introduced into the zeolites either from solutions in water, chloroform, acetonitrile, hexane, and toluene, $\dagger$ or via vapour-phase adsorption. $\ddagger$ Spontaneous polymerization occurs after about 30-120 min, depending on the zeolite host and experimental conditions, e.g. reaction (1). Bulk polymers were prepared chemically by oxidative polymerization with $\mathrm{Fe}\left(\mathrm{ClO}_{4}\right)_{3}$ in $\mathrm{MeCN} .{ }^{7,8}$

$$
\mathrm{Cu} I \mathrm{Y}+\mathrm{C}_{4} \mathrm{H}_{4} \mathrm{~S} \stackrel{\text { vapour, } 295 \mathrm{~K}}{\longrightarrow} \mathrm{CuY} / \text { polythiophene }
$$

If thiophene monomers are admitted into the metal zeolites $\mathrm{Y}$ or $\mathrm{M}$ from the vapour phase or from hexane and toluene solutions, the colours of the resultant adducts change slowly from white to different shades of blue or dark green. No reaction is observed with $\mathrm{Cu}^{\mathrm{II}} \mathrm{A}$, with the zeolite sodium forms, and in treatments of metal zeolites in polar solvents $\left(\mathrm{H}_{2} \mathrm{O}\right.$, acetonitrile, etc. $)$. The $\mathrm{Cu}^{\mathrm{II}}$ forms of $\mathrm{Y}$ and $\mathrm{M}$ generally

$\dagger$ Dry zeolite $(0.500 \mathrm{~g})$ was stirred for $12 \mathrm{~h}$ in $25 \mathrm{ml}$ of solvent with 8.0 and 1.3 monomer molecules per $\mathrm{Y}$ and $\mathrm{M}$ unit cell, respectively.

$\ddagger \mathrm{V}$; equilibrated in a quartz reactor at $295 \mathrm{~K}$ under $c a$. 1 Torr for $1 \mathrm{~h}$, pumped for $30 \mathrm{~min}$, resulting in $25-35(\mathrm{Y}), 1-2(\mathrm{M})$, and $0.2(\mathrm{~A})$ monomer molecules per unit cell. produce a slightly higher polymer yield than the FeIII forms. From the estimated surface capacity of the zeolite crystals ( $c a$. 0.2 molecules/unit cell of $Y$, based on $1 \mu \mathrm{m}$ crystals) and the observed monomer loadings $\ddagger$ we conclude that most of the monomer molecules are introduced into the pore system of the zeolite host.

Neutral P3MTh films (formed electrochemically) show absorption in the visible region at about $2.5 \mathrm{eV}$ associated with the $\pi \rightarrow \pi^{*}$ transition of long conjugated polymer chains. 9,10 When the polymer is oxidized, two intra-gap absorptions develop at about 0.65 and $1.6 \mathrm{eV}$. With progressive oxidation, the $2.5 \mathrm{eV}$ absorption decreases in intensity. The two former bands have been assigned to bipolaron transitions. The electronic absorption spectrum of $\mathrm{Cu}_{15} \mathrm{Na}_{26} \mathrm{Y} / \mathrm{P} 3 \mathrm{MTh} / \mathrm{V}$ shows features at about $450 \mathrm{~nm}(c a .2 .8 \mathrm{eV}), 600 \mathrm{~nm}(2 \mathrm{eV})$, and $730 \mathrm{~nm}(1.7 \mathrm{eV}) . \mathrm{Cu}_{2.4} \mathrm{Na}_{3.2} \mathrm{M} / \mathrm{P} 3 \mathrm{MTh} / \mathrm{V}$ shows bands at 450 and $540 \mathrm{~nm}$ (2.8 and $2.3 \mathrm{eV}$ ), and absorption extending

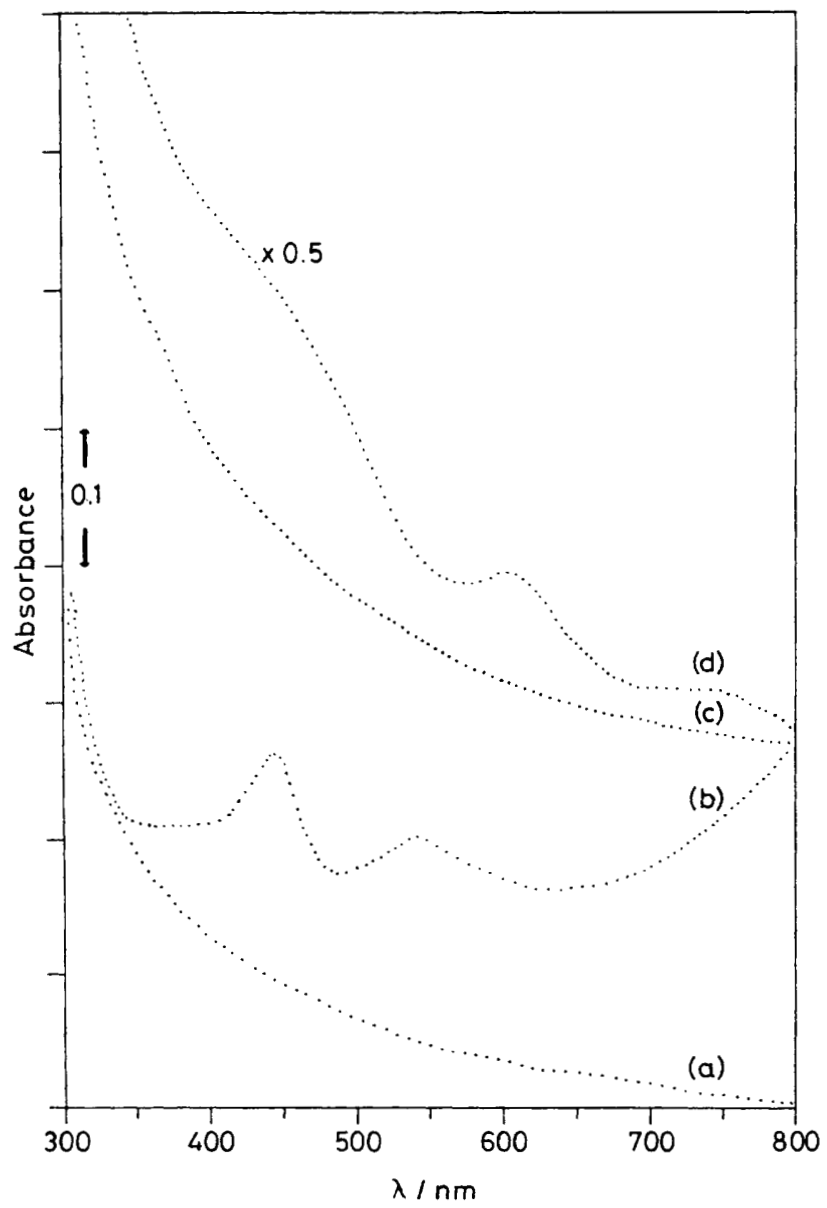

Figure 1. Electronic absorption spectra of $\mathrm{Cu}^{\mathrm{II}}$ zeolites and poly $(3-$ methylthiophene) in $\mathrm{Cu}$ zeolites $(1.5 \mathrm{mg}$ zeolite dispersed in $1.0 \mathrm{ml}$ glycerine; spectra are offset): (a) $\mathrm{Cu}_{2.4} \mathrm{Na}_{3.2} \mathrm{M}$; (b) $\mathrm{Cu}_{2.4} \mathrm{Na}_{3.2} \mathrm{M}$ / P3MTh/V; (c) $\mathrm{Cu}_{15} \mathrm{Na}_{26} \mathrm{Y}$; (d) $\mathrm{Cu}_{15} \mathrm{Na}_{26} \mathrm{Y} / \mathrm{P} 3 \mathrm{MTh} / \mathrm{V}$. 


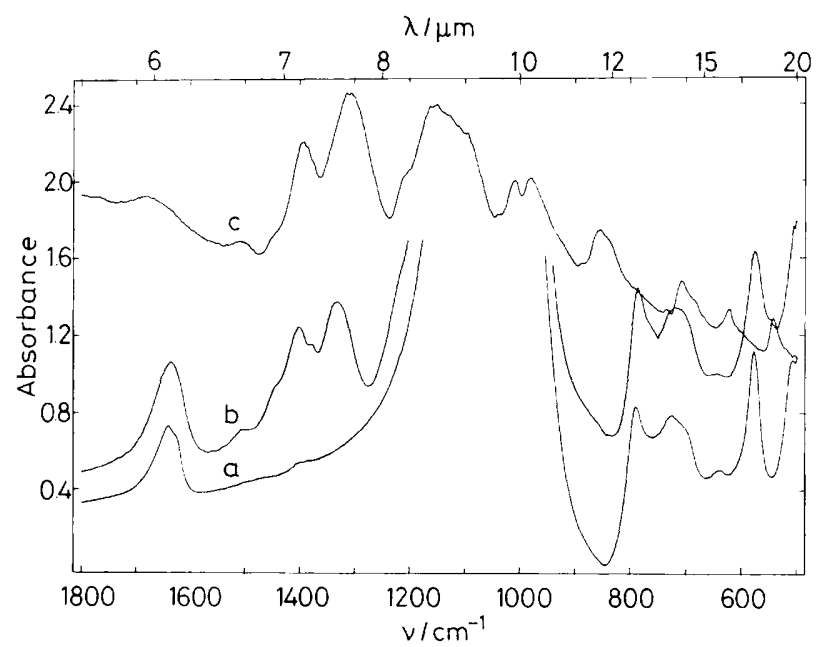

Figure 2. Fourier transform i.r. spectra of zeolite and poly(3methylthiophene) samples ( $\mathrm{KBr}$ pellets; $4 \mathrm{~cm}^{-1}$ resolution): (a) $\mathrm{Na}_{56} \mathrm{Y}$; (b) $\mathrm{Cu}_{15} \mathrm{Na}_{26} \mathrm{Y} / \mathrm{P} 3 \mathrm{MTh} / \mathrm{V}$; (c) bulk poly(3-methylthiophene).

into the near i.r. $(<1.7 \mathrm{eV}$; Figure 1$)$. Comparable features

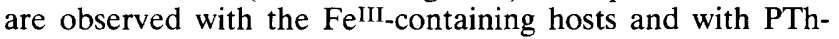
loaded zeolites. The intrazeolite polymers have more complex spectroscopic features than the bulk materials. From the simultaneous observation of interband transitions (ca. $2.8 \mathrm{eV}$ ) and the red/near i.r. absorptions, we conclude that the polymer chains on average are at intermediate oxidation levels in both zeolites. The additional bands at $2 \mathrm{eV}(\mathrm{Y})$ and $2.3 \mathrm{eV}$ (M) probably reflect different polymer chain-length distributions and/or different oxidation levels imposed by the zeolite host structures. We note that the electronic transitions of decoupled chains could be expected to differ from those of bulk materials.

The i.r. spectrum of $\mathrm{Cu}_{15} \mathrm{Na}_{26} \mathrm{Y} / \mathrm{P} 3 \mathrm{MTh} / \mathrm{V}$ shows typical vibrations of poly(3-methylthiophene $)^{11,12}$ at $1506 \mathrm{w}, 1400 \mathrm{~s}$, 1331s, and $712 \mathrm{w} \mathrm{cm}^{-1}$ (Figure 2; the spectral range between 1200 and $900 \mathrm{~cm}^{-1}$ is blocked by zeolite framework absorptions). It also shows a characteristic tail of the electronic transition correlated with the presence of free carriers in highly conducting polythiophenes. ${ }^{13}$ In particular, the presence of the intense, fairly broad peaks at 1400 and 1331 $\mathrm{cm}^{-1}$ indicates that the polymer chains are in the oxidized form. ${ }^{12}$ Minor contributions of neutral polymer will be obscured because the respective absorption coefficients are much smaller. Certain shifts between i.r. frequencies of bulk P3MTh and the zeolite/P3MTh hybrids suggest some interaction of the polymer with the host. The zeolite framework functions as a three-dimensional anion for the charged polymer chains. The intrazeolite polythiophenes can be recovered by dissolution of the zeolite host in HF; i.r. spectra of the blue-black agglomerated products are comparable to those of chemically synthesized bulk materials.

The following observations demonstrate that the polythiophene chains form within the zeolite pore systems. (i) PTh and P3MTh are formed in the zeolites at rates that are orders of magnitude slower than in solution reactions, indicating that the monomers must diffuse though the channels to reach the intrazeolite oxidant. Polymers are not formed in zeolite A where the small pore opening of $0.4 \mathrm{~nm}$ does not allow for monomer diffusion into the zeolite pores and oxidation by intrazeolite oxidants. The above diffusion and pore-volume limitations would not have been observed if the polymers had only formed on the crystal surfaces. (ii) Polymerization takes place only in the presence of oxidant ions which are available at significant levels inside the ion-exchanged zeolite crystals. Accordingly, no polymers are formed in the Na-forms. (iii) Pressed zeolite/polymer pellets show no significant 'bulk' conductivity $\left(\sigma<10^{-8} \mathrm{~S} / \mathrm{cm}\right)$; therefore, there is no noticeable deposition of polymer present on the external crystal surfaces. Agglomerated P3MTh recovered from $\mathrm{Cu}_{15} \mathrm{Na}_{26} \mathrm{Y} / \mathrm{P} 3 \mathrm{MTh} / \mathrm{V}$ after dissolution of the host in HF shows a conductivity of about $0.01 \mathrm{~S} / \mathrm{cm}$. (iv) Scanning electron micrographs indicate no evidence of polymer covering the surfaces of zeolite/ polymer crystals. (v) Pyrolysis mass spectrometry detects considerably less monomer evolution from the zeolite/polymer samples than from those containing unreacted monomers (e.g., Na-forms), as expected if polymerization has taken place. (vi) Polymerization from the vapour phase and from non-polar solvents is favoured over reactions from polar solvents, probably because the intrazeolite metal ions are screened by the polar solvent molecules.

In summary, this study demonstrates that it is possible to polymerize Th and 3MTh within the channel systems of zeolites, analogous to the oxidative coupling of Th and 3MTh in solution in the presence of $\mathrm{Cu}^{\mathrm{II}}$ and Fe $\mathrm{Fe}^{\mathrm{III}}$ oxidants. ${ }^{7,8}$ While the polymerization proceeds only if oxidant ions are present in the zeolite pores, the degree of chain oxidation and probably the chain lengths are influenced by the dimensionality of the zeolite channels.

This is the first approach to the stabilization of 'molecular wires' of polythiophenes in a stable, well-defined host. The transport properties of these and other intrazeolite polymers such as polypyrrole ${ }^{14}$ and polyaniline ${ }^{15}$ are presently being studied.

We acknowledge financial support from the National Science Foundation for instrumentation used in this research.

Received, 24th May 1989; Com. 9/02203A

\section{References}

1 'Proceedings of the International Conference on Science and Technology of Synthetic Metals,' ICSM '88; ed. M. Aldissi, Synth. Metals, 1989, 28 (1-3), 29 (1).

2 F. L. Carter, 'Molecular Electronic Devices II,' Dekker, New York, 1987.

3 G. Tourillon, 'Handbook of Conducting Polymers,' ed. T. A. Skotheim, Dekker, New York, 1986, vol. 1, p. 293.

4 D. W. Breck, 'Zeolite Molecular Sieves,' R. E. Krieger, Malabar, FL, 1984; R. Szostak, 'Molecular Sieves. Principles of Synthesis and Identification,' Van Nostrand Reinhold, New York, 1989.

5 P. K. Dutta and M. Puri, J. Catal., 1988, 111, 453.

6 M. G. Kanatzidis, M. Hubbard, L. M. Tonge, T. J. Marks, H. O. Marcy, and C. R. Kannewurf, Synth. Metals, 1989, 28, C89.

7 N. Mermilliod-Thevenin and G. Bidan, Mol. Cryst. Liq. Cryst., $1985,118,227$.

8 M. B. Inoue, E. F. Velazquez, and M. Inoue, Synth. Metals, 1988, 24, 223.

9 G. Dian, G. Barbey, and B. Decroix, Synth. Metals, 1986, 13, 281.

10 N. Colaneri, M. Nowak, D. Spiegel, S. Hotta, and A. J. Heeger, Phys. Rev. B, 1987, 36, 7964.

11 J. E. Osterholm, P. Sunila, and T. Hjertberg, Synth. Metals, 1987, 18, 169.

12 H. Neugebauer, G. Nauer, A. Neckel, G. Tourillon, F. Garnier, and P. Lang, J. Phys. Chem., 1984, 88, 652.

13 S. Hotta, W. Shimotsuma, and M. Taketani, Synth. Metals, $1984 / 85,10,85$.

14 T. Bein and P. Enzel, Angew. Chem., submitted.

15 P. Enzel and T. Bein, J. Phys. Chem., in the press. 